\title{
EJSBS
}

The European Journal of Social \&

Behavioural Science

ISSN: 2301-2218 (ONUINE)
OPEN ACCESS

\section{THE CHALLENGES OF FORENSIC LINGUISTIC ANALYSIS OF FALSE TESTIMONY}

\author{
Galyashina Elena Igorevna ${ }^{\text {a* }}$ \\ ${ }^{a}$ Department of Forensic Expertise, Kutafin Moscow State Law University (MSAL), Sadovaya-Kudrunskaya Str., 9, \\ Moscow, 123995, Russia
}

\begin{abstract}
The present paper arises from wider research which focused on various manifestations of destructive and malicious speech behavior in spontaneous oral or written dialogs, related to the processes of information concealment and falsification in police interviews and court testimonies. A number of analytical methods were used to generate this paper: a retrospective analysis of scientific literature, comparative legal and logical analysis, extrapolation methods, and content analysis. Despite numerous experimental researches devoted to acoustic-phonetic or psycholinguistic features of lies, their results are not sufficiently reliable for forensic purposes as the expert report should not rely on assumptions. The author disputes the evidence admissibility of experts' conclusions about utterances implying speech parameters correlating with lies detected via psycholinguistic examination in oral speech audio or video recording of a police interview or a court testimony. Forensic psycholinguistic methods and comprehensive algorithms used in some forensic experts' reports to detect speech signs of lying demonstrate a great variety that contradicts with the principals of evidence admissibility. The insufficient development of the currently used expert approach and the lack of a unified methodology for solving expert tasks on a strictly scientific basis creates a demand for developing comprehensive methods for studying lies on the basis of forensic speech science and cognitive theory.
\end{abstract}

Keywords: Lies, deceit, testimony, forensic linguistics, evidences, validity

(C) 2021 Published by European Publisher. www.europeanpublisher.com

${ }^{*}$ Corresponding author. Tel.: +7-909-628-23-86.

E-mail address: eigalyashina@gmail.com

doi: $10.15405 /$ ejsbs.302 
https://doi.org/10.15405/ejsbs.302

eISSN: 2301-2218 / Corresponding Author: Galyashina Elena Igorevna

Selection \& Peer-review under responsibility of the Editors

\section{Introduction}

The false testimony of a witness, a plaintiff, an expert or an interpreter in the criminal proceedings is an action directed against the interests of justice. Despite the prevalence of false testimonies with its attendant consequences of significant public danger, countermeasures against such false testimonies have not been actively sought. Judges and investigative agencies lack knowledge about the utilization of forensic methods to detect false statements and the mechanisms used to generate such statements. Forensic linguists and psychology experts' practice of speech lie detection is rather ambiguous. Theoretical and practical problems are associated with the absence or incorrect interpretation of the subject, object, tasks and methods of this expertise. Studies aimed at identifying signs of possible deception or "falsity" of information provided by participants in judicial or investigative processes are conducted contrary to existing legal requirements, most often in a comprehensive manner (Engalychev et al., 2016).

The Ministry of Justice of the Russian Federation made an attempt to resolve the legal problems that arose in the production of forensic examinations to identify signs of reliability/unreliability of information provided by participants in the criminal proceedings "on the illegality of determining the reliability of testimony by forensic examination" fixed the provision on the impossibility of conducting such examinations on a strictly scientific basis (Smirnova et al., 2016, p. 69). However, many experts have sustained their inquiry into overcoming the existing obstacles in the field of diagnosing verbal and nonverbal signs of deception in the framework of forensic linguistic research (Amado et al., 2015; Halfmann \& Sporer, 2015). In crime investigation practice there are known cases when an audio recording of a witness or victim testimony becomes the decisive evidence without any possibility for the person to be present at the trial (Köhnken et al., 2015).

According to Kirchhübel (2013),

A greater understanding of the acoustic and temporal characteristics of speech elicited during situations when one is trying to hide something or lie has potential benefit to a number of professions. Law enforcement agencies, such as the police, would be aided if they could tell if their suspect is lying or telling the truth during an interview. Similarly, intelligence agencies, the military and security officers would benefit from being able to use 'reliable' means of detecting deception. (p. 24)

\section{Purpose of the Study}

The purpose of the study is to validate, in Russian criminal legislation, the possibility of implementing the existing expert approach of deception detection in situations when it is 
https://doi.org/10.15405/ejsbs.302

eISSN: 2301-2218 / Corresponding Author: Galyashina Elena Igorevna

Selection \& Peer-review under responsibility of the Editors

impossible for a person to be present at the trial (because he/she is dead, gravely ill, incapacitated) and his/her recorded statement or assertion is the only evidence available). Kirchhübel (2013) contends that "Forensic Speech Science is a relatively young but growing field of research, applying knowledge gained from linguistics, phonetics, dialectology and sociolinguistics, in combination with expertise from speech and sound analysis for use in legal investigations and proceedings" (p. 24). The reason why more focussed research needs to be dedicated to the detection of deception in the criminal context is because forensic speech practitioners' expertise is often called upon to evaluate the statements of the accused in terms of their existence of deceptiveness (Kirchhübel, 2013).

This situation is aggravated by the fact because of the lack of an authenticated and valid framework to detect deception in speech utterances, such 'evaluations' are currently prohibited by the International Association of Forensic Phonetics and Acoustics (IAFPA code of practice 2020, clause 3.11). According to the webpage of the Association,

The International Association for Forensic Phonetics and Acoustics (IAFPA) is the professional association for forensic scientists and researchers who analyse voices, speech and audio recordings. The organisation seeks to foster research and provide a forum for the interchange of ideas and information on practice, development and research in forensic phonetics and acoustics, and to set down and enforce standards of professional conduct and procedure for those involved in forensic phonetic and acoustic casework - members are therefore bound by a Code of Practice" (https://www.iafpa.net/, n.p.)

According to this, members must not attempt to do psychological profiles or assessments of the truthfulness of speakers. This puts the police and other investigating agencies at a disadvantage, as they are unable to verify suspects' and witnesses' utterances as truth or deception. This could hamper criminal proceedings and even lead to inaccurate court judgements.

\section{Research Question/s}

The research question can be formulated as follows: what are the distinguishing characteristics of speech utterances with specific focus to lies/deception within the context of giving false testimony? Is it possible to reveal evidential signs of lies/deception in oral speech?

\section{Research methods}

In order to answer the research question, a number of tasks was undertaken. These involved monitoring of contemporary judicial practice of Russian criminal proceedings in the 
https://doi.org/10.15405/ejsbs.302

eISSN: 2301-2218 / Corresponding Author: Galyashina Elena Igorevna

Selection \& Peer-review under responsibility of the Editors

database SudAkt (https://sudact.ru) - the Internet resource of court decisions, judicial and regulatory documents of the Russian Federation - in order to identify cases in which expert conclusions about the presence of lie signs in the testimony or in a police interview were admitted as evidence in court; analysis of written expert reports for their validity; systematization of distinguishing linguistic-acoustic characteristics of speech utterances with specific focus to lies/deception within the context of giving false testimony.

The investigation focused on the scientific-methodological basis for assessing the diagnostic relevance of speech signs detected by experts as a lie. The empirical base of the study was formed by forensic practice of expert examinations of false testimony. The following set of methods was used to elicit the required data for the study: a retrospective analysis of scientific literature; comparative legal and logical analysis; extrapolation methods; general scientific investigative methods such as analysis, synthesis, deduction, and induction in tandem with specific scientific research methods; as well as extracting and incorporating knowledge from interrelated scientific fields of criminology, criminal procedure, psychology and linguistics that form the methodological basis of the research.

\section{Findings and Discussion}

\subsection{Lies and deception in a speech act}

The phenomenon of lying is one of the most difficult to study in natural and social sciences. Lying is a purely social phenomenon and arises in connection within the context of human communication. A person, as a subject of interpersonal communication, uses innuendoes, understatements, figures of silence, concealments etc. to achieve pragmatic goals that meet his/her interests. Those in dealing with information can either resort to deception themselves or be deceived by others. This is an inherent part of any social communication and may occur in any speech interaction. Lying in the social sciences is analyzed in conjunction with such concepts as "untruth", “deception", “delusion”, “defraud”, etc. and is considered as a person's cognitive activity with a deception goal that manifests itself in interpersonal speech communication and demeanor (Eckman, 2009). So, speech markers of lying can help to spot testimony deception and thus, might be of the particular interest for forensic speech examiners.

Speech act theory (Searle, 1979) states that any utterance (usually a sentence) contains a propositional content part and an illocutionary force. Speech act theory is important in testimony deception detection for two reasons. First, all kinds of untruths and, as a result, deceptions are transmitted by verbal and nonverbal means. Second, it provides an approach to the forensic linguistic examination of a witness testimony as statements and assertions represent the typical illocutory acts in the police interview (Adler, 1997; Alston, 2000; 
https://doi.org/10.15405/ejsbs.302

eISSN: 2301-2218 / Corresponding Author: Galyashina Elena Igorevna

Selection \& Peer-review under responsibility of the Editors

Zuckerman \& Driver, 1985). When people lie, they will attempt to control their words to a greater extent; namely, to monitor the semantic content. When trying to mislead their listeners, liars usually do not think about controlling nonverbal manifestations, believing that the interlocutor is not paying due attention to facial expressions or prosody due to the peculiarities of the human brain.

Speech is much more convenient for lying, since when it is reproduced, people can additionally hear themselves and, based on what they hear, can build a logical chain and adjust further statements for a more plausible transmission of information. It is more difficult to control facial expressions and especially the intonation of the voice.

The main expert challenge is to define lying as a speech act and to decide whether a given utterance of a speaker recorded during the police interview or court testimony possess signs of lying that could be conceded to be deception and criminalized as perjury.

There is a variety of different definitions of lying (Mahon, 2015) that can be grouped into three main categories. The first definition refers to any lie is intended to be deceptive (Mahon, 2008). The second is an assertion-based definition that consider lies as assertions - a person asserts (states) something that can be verified - the information can be checked for compliance with reality at the time to which the statement relates (Green, 2000; Green, 2001; Green, 2017). The third category incorporates both requirements and is valid to define a knowingly false testimony that can be criminalized as a perjury in a court of law.

Deceptive speakers may express more uncertainty in their statements and this uncertainty can be detected in the type of speech acts speakers use. For example, uncertain speakers tend to use more opinions, expressions, and tail-questions than truthtellers (Twitchell et al., 2004). Unreliable information may be correlated with the emotional experiences of a person, such as guilt, shame, emotional uplift (Vrij, 2000). The number and duration of pauses increases, when liars attempt to select the appropriate words to couch their lies. Also, to delay the response time, the interviewed person can repeat the question or pause longer. The number of filled and unfilled pauses-hesitation increases in comparison with nondeceptive speech utterances of the same person. Changes in speech features such as intensity, pitch, hesitations and staccato bursts may accompany deception as, when people are being deceptive, their pitch, energy, rhythm patterns and speaking rate may unconsciously change. Focused research has been carried out on the vocal correlates of deception irrespective of the presence and level of stress. But the most of experimental data from this research can be disputed with regard to the strict correlation between acoustic phonetic features and indications of stress/lies present in the speech. Thus, while it has been posited that the fundamental frequency of a speaker rises as a function of lying, experimental findings did not show statistically significant results 
(Ekici, 2016). Temporal analysis may be applied only in very specific settings and needs to take into account situational and individual factors (Kirchhübel et al., 2013). The known vocal correlates of stress and lying are so tenuous that they cannot serve as evidence in court as there is no measurement of vocal parameters having a strict correlation with lying. In recent decades, the attention of researchers has been directed to oral speech corpora creating, in particular, Columbia-SRI-Colorado $(\mathrm{CSS})^{1}(2013)$ which includes texts of both truthful and insincere statements. According to Levitan et al. (2016), the inclusion of distinguishing signs of gender, language proficiency and personal characteristics in combination with acousticprosodic characteristics of speech increases the accuracy of detecting signs of lying in oral speech. Currently, automatic deception detection is carried out using artificial intelligence and machine learning systems that include classifiers of signs of insincere speech, the number of which is quite large, for example, the basic set of Interspeech 2009 (IS09) ${ }^{2}$ ComParE Challenge functions contains 384 acoustic-prosodic characteristics (Eyben et al., 2010).

\subsection{False testimony and perjury in Russian legislation}

Perjury is a crime that is expressed in the deliberate giving of false factual information to law enforcement agencies, courts or authorities. Knowingly false testimony damages citizens belief in justice and restricts human and civil rights and freedoms including the right to a fair trial.

Testimony is one of the most important procedural means by which the establishment of the circumstances of a criminal case and the solution of other tasks facing the justice system are ensured.

Taking into account the significance of the testimony of various participants involved in the criminal proceedings, the law establishes the obligation to testify as one of the most important legal obligations of citizens (Article 42, 56 of the Criminal Procedure Code of the Russian Federation), failure to comply with which in the form of refusal to testify or giving deliberately false testimony may lead to criminal liability (Article 307, 308 of the Criminal Code of the Russian Federation). So, in Russian legislation, perjury is the part of a more general Article 307 of the Criminal Code of the Russian Federation, which includes knowingly false testimony, the conclusion of an expert, specialist or incorrect translation.

\footnotetext{
1 "CSC Deceptive Speech was developed by Columbia University, SRI International and University of Colorado Boulder. It consists of 32 hours of audio interviews from 32 native speakers of Standard American English (16 male,16 female) recruited from the Columbia University student population and the community. The purpose of the study was to distinguish deceptive speech from non-deceptive speech using machine learning techniques on extracted features from the corpus" (Introduction, CSC Deceptive Speech, 2013)

2 This INTERSPEECH 2009 Emotion Challenge was undertaken to close the gaps between research on human emotion recognition from speech and low compatibility of results (Schuller, Steidel, Batliner, 2009)
} 
https://doi.org/10.15405/ejsbs.302

eISSN: 2301-2218 / Corresponding Author: Galyashina Elena Igorevna

Selection \& Peer-review under responsibility of the Editors

Knowingly false testimony of a witness, an expert, a specialist, as well as knowingly incorrect translation in court or during the preliminary investigation are punishable by a fine of up to eighty thousand rubles or in the amount of the convicted person's salary or other income for a period of up to six months, or compulsory labor for a period of 180 to 240 hours, or correctional labor for a period of up to two years, or arrest for a period of up to three months. The same acts connected with the accusation of a person in the commission of a serious or particularly serious crime are punishable by imprisonment for up to five years. An expert, a specialist or an interpreter are interrogated according to the rules of a witness testimony during a police interview in the pre-trial proceedings in a criminal case or in court. The testimony is assessed by the jury or the judge as evidence for relevance, admissibility and reliability. A witness, victim, expert, specialist or translator are exempt from criminal liability if they voluntarily, in the course of pre-trial proceedings or court proceedings before the court's verdict or decision, declared the falsity of their testimony, conclusion or deliberately incorrect translation. The purpose of the expert's interrogation is clarification or supplement of the expert's written report. A specialist is invoked to help the trial to study special scientific or technical aspects that does not require the examination of material evidences.

According to Article 52 of the Constitution of the Russian Federation, the rights of victims of crimes are protected by law, and the state must provide them with access to justice and compensation for the damage caused. By virtue of paragraph 1 of Part 1 of Article 6 of the Criminal Procedure Code of the Russian Federation, criminal proceedings are intended to protect the rights and legitimate interests of persons and organizations that have suffered from crimes. In accordance with Article 78 of the Criminal Procedure Code of the Russian Federation, the victim's testimony is recognized as information that he/she has informed the inquirer, investigator or court about any circumstances that are subject to proof in a criminal case. As a rule, the victim's testimony concerns the circumstances of the crime committed against him/her or his/her property, the relationship with other victims in this case, witnesses, as well as the suspect and the accused. Evidentiary value in the testimony of a victim, as well as a witness, has only the factual information they reported, expressed in the form of a statement about a fact or event that can be verified for validity at the time to which it relates.

The testimony of a witness or a plaintiff in a criminal case is obtained during the interrogation about any circumstances relating to the event of the crime, the persons involved in it, the victims or other witnesses. A special feature of the interrogation is its oral, volitional nature (the person voluntarily, without coercion, verbally reports the actual data. The witness, as a general rule, poses a reliable factual information about which he/she is personally aware or can name the source of his/her knowledge. It presumes a doctrine that witnesses generally 
https://doi.org/10.15405/ejsbs.302

eISSN: 2301-2218 / Corresponding Author: Galyashina Elena Igorevna

Selection \& Peer-review under responsibility of the Editors

must state the facts and not their inferences, conclusions, or opinions. Although facts and opinions stand in contrast, they are not easily distinguishable in a speech act.

False testimony is usually represented by two phenomena: concealment and falsification. When concealing, a witness, a victim or a plaintiff withholds some information, silencing a fact or a circumstance that had occurred in reality. If information is falsified, then untrue data it is presented under the guise of truthful. The motives for reporting deliberately false information can be very different, both intentional and unintentional. It may be fueled by a desire to avoid punishment or it may be a sincere delusion in the innocence of a person; it may also be personal (non-selfish motives) associated with the unwillingness to face the consequences if the case takes an undesirable turn for one of the parties, and many others. False testimony of a witness or a victim may appear in the materials of a criminal case not only as a result of their" malicious intent to deceive", but also because they could have been forced to give evidence by an investigator, inquirer or some other person with their knowledge or tacit consent. In addition, false testimony of a witness or a victim may be related to their bribery or coercion to give evidence by other persons, either participating in the case or not having anything to do with it.

At the same time, the Constitution of the Russian Federation establishes as one of the inalienable rights of any person not to testify in a court or other body against himself, his spouse and close relatives. This right serves as a guarantee that ensures the dignity of a person (art. 21), the inviolability of his private life, personal and family secrets (art.23, 24), the possibility of protecting his rights and freedoms (art. 45), the consideration of cases in courts on the basis of the presumption of innocence and adversarial proceedings (art. 49, 123).

Thus, it can be concluded that the testimony is considered false and qualifies as perjury if the person who provides the deliberately false information has the procedural status of a witness, victim, expert, specialist in the criminal or civil proceedings; the information provided by the interrogated person is deliberately fully or partly distorted; the information provided by the person during the interrogation is considered as evidence; the testimony is conducted in a procedural form determined by the law.

\subsection{Statement, opinion and assertion in the context of truth verification}

A statement is an oral assertion of a person if it is intended as an assertion. The word assert in the context of trial testimony means to state positively that event has happened, the condition or circumstance existed or exists. From a linguistic point of view, an assertion expresses factual information about an event, process, phenomenon that occurred in the past or is happening at the present time, in specific conditions of a place and time. It can be either 
https://doi.org/10.15405/ejsbs.302

eISSN: 2301-2218 / Corresponding Author: Galyashina Elena Igorevna

Selection \& Peer-review under responsibility of the Editors

true or false, if the factual information transmitted by the means of language can be checked for its truth or falsity. A statement of fact is a statement in which information about a fact (state of affairs) or the actions of a person (event) is given in verbal form, in a predicate group and is understood by the audience as important, and new. It is presented as reflecting the state of affairs, which does not depend on the perception, comprehension, or attitude of the speaker. Grammatically, a statement about a fact or event is displayed through indicators of objective modality (in the form of an indicative mood) and is recognized in the text by the absence of markers of subjective modality, evaluative words and constructions, and other indicators expressing uncertainty, or doubt of the speaker in the reliability of the reported. A statement about a fact is grammatically expressed in the form of a narrative sentence - both nonexclamation and exclamation. A statement of fact may contain constructions that emphasize the reliability of the information being reported.

An opinion, in contrast to statements about a fact, implies an indication of the carrier of the opinion. The expression of an opinion is recognized in the text by the presence of certain words and constructions indicating it (for example, in my opinion, I believe, I think, etc.). An opinion, unlike a statement about a fact, cannot be true or false, but it may or may not be confirmed by facts, and events of objective reality. An opinion can be formed on the basis of facts or it can be biased; not based on facts. People can form opinions consciously, rationally evaluating the facts, or unconsciously, without giving an account of why they think so. The opinion contains information, but not about the reality itself (facts), but about what kind of image of reality the speaker has, and what their attitude to the events described is. It is important to note that statements of facts can be inserted into statements of opinion.

An assumption, in contrast to a statement about a fact, contains special markers - words expressing uncertainty, doubt, the probability of the origin of an event, or one of a number of possible versions (for example, it may be, probably, possible, etc.). An assumption, in fact, is one of the forms of expression of opinion when the speaker wants to emphasize the preliminary nature of the expressed arguments.

A value judgment is a type of opinion containing a positive or negative assessment of someone or something. The information transmitted in various forms of opinion does not reflect the real reality, not the real world, but the image of reality that exists in the individual consciousness of the speaker - a possible world, as logicians and linguists call it, or a picture of the world. The picture of the world is studied and described in special terms, but is not evaluated by the falsity/truth parameter. The expression of evaluation is recognized in the text by the presence of certain evaluation words and constructions, including emotionally expressive modal in which meaning it is possible to distinguish the elements of "good / bad" 
https://doi.org/10.15405/ejsbs.302

eISSN: 2301-2218 / Corresponding Author: Galyashina Elena Igorevna

Selection \& Peer-review under responsibility of the Editors

or their specific varieties (good, evil, etc.). In the presence of a positive assessment (the element "good" and its specific varieties), we can talk about positive information. If there is a negative assessment (the "bad" element and its specific varieties), we can talk about negative information.

Evaluative statements that establish the absolute or comparative value of an object include assessments themselves (reflecting, in particular, the basis-conclusion relationship), as well as conventions and ideals. The evaluation of an object, although based on a certain knowledge about it, is not a description and, accordingly, cannot be true or false. It follows from this that an evaluative statement cannot be verified as corresponding to reality or not - it can only be challenged.

\subsection{Differentiation of value judgments, opinions and statements about facts.}

In order to detect untruth in false testimony it is necessary to distinguish between statements about facts, the validity of which can be checked for truth or falsity, and value judgments, opinions, which, being an expression of subjective assessments and views, cannot be checked for truth or falsity, reflecting the author's picture of the world (Gogin \& Repeteva, 2017). Formal-semantic and pragmatic criteria are used to distinguish information, reports about facts, and value judgments. It is also necessary to consider the following premises. The existence of facts can be verified and proved, as well as the truth of statements about facts, while the truth of value judgments cannot be verified. It is necessary to determine in what language form the information is expressed, and also to establish whether the information can be verified from the point of view of their semantics (the internal content of the statement). To distinguish between a statement of fact and an opinion, you can also use a formal linguistic criterion - the belonging of individual speech fragments of the police interview or trial testimony to the class of descriptive or evaluative statements (Plotnikova et al., 2018).

Descriptive statements contain information about facts and events: they state the state of affairs or affirm the necessary connection of phenomena. In most cases, they have the grammatical form of a narrative sentence and are subject to verification; that is, they can be checked for truth or falsity (compliance or non-compliance with reality).

Factual information can be expressed explicitly and implicitly in the oral assertion. Explicit statements about facts fully or almost completely correspond to the external form of the statement. Understanding their meaning does not require semantic transformations of the source text from the listener (police enforcement officer, a judge or jury). Understanding implicit information requires additional semantic transformations. Such transformations involve taking into account semantic connections, the previous or subsequent context in which 
https://doi.org/10.15405/ejsbs.302

eISSN: 2301-2218 / Corresponding Author: Galyashina Elena Igorevna

Selection \& Peer-review under responsibility of the Editors

the implicit information is distributed or included. If the implicit information has the property of a mandatory consequence determined by the context, then it is considered as a special kind of statement about a fact - a hidden statement about a fact (Galyashina, 2020).

Mandatory consequences are those consequences that are necessary for understanding a sentence, a fragment of the text in which they are included, or the text itself; if the listener does not identify the mandatory consequences, the utterance will turn out to be semantically incomplete - incoherent, unmotivated, semantically anomalous, etc. Explicit information directly follows from the dictionary meanings of the words used in the utterance; its content can be established from the language form of the utterance, without carrying out additional semantic transformations. Implicit information is revealed on the basis of additional understanding of the meaning of words and expressions through syntactic constructions included in the utterance on the basis of the structure of the utterance taking into account the entire context and the situation of using this utterance. Both explicit and hidden statements about facts, regardless of the degree of their concreteness, can be checked or verified from the point of view of compliance with reality. The essential features of the expression of both explicit and implicit information in the form of a statement of fact are as follows:

- a narrative sentence with a predicate in the form of an indicative mood (indicative);

- the absence of markers of opinion and assumption;

- the possibility of verification (a statement about facts that can be checked for compliance with reality).

In order to determine assertion, methods of lexical semantics analysis are used (the meanings of individual words in the context are determined) and the linguistic theory of the text (the meanings of individual phrases within the entire text or its parts are determined taking into account the meaning of the syntactic constructions included in these phrases) (Izotova et al., 2016).

\section{Conclusion and Implications}

In spite of the experimental data gathered by research in this area, the results cannot be relied upon to prove, without a doubt, the occurrence of lies/deception in a statement which can then be accepted as an admissible evidence of false testimony.

Some acoustic-prosodic signs in oral speech can serve as episodic indicators of lies, since they depend on the effect of various factors such as gender, psychotype, degree of language proficiency, etc. towards the reliability/unreliability of information is currently insufficiently studied. Linguistic-prosodic signs of false utterances in oral speech seem to be 
https://doi.org/10.15405/ejsbs.302

eISSN: 2301-2218 / Corresponding Author: Galyashina Elena Igorevna

Selection \& Peer-review under responsibility of the Editors

more reliable indicators, but their reliability also needs further research to verify which prevents their use as speech evidence of deception currently.

The practice of the highest judicial bodies of the Russian Federation follows the path of "non-recognition" as acceptable evidence of expert conclusions (psychological, complex psychological-linguistic, psychological-psychiatric and other types of examinations), where the task was to identify signs of reliability/unreliability of testimony recorded on audio or video gadgets. The Supreme Court of the Russian Federation has stated that legal issues cannot be put before an expert, including those related to the assessment of truthfulness or falsity of testimony; that is, the reliability or unreliability of the suspects' testimony given by them during the course of investigative actions (Appeal ruling of the Judicial Board for Criminal Cases of the Supreme Court of the Russian Federation, 2017) Subsequently, these expert reports were excluded as inadmissible evidence.

Thus, it can be concluded that despite the increasing practice of applying knowledge either directly or indirectly from the fields of psychology, physiology, psycholinguistics, psychiatry and other related areas to human speech activity, in order to identify signs of reliability, truthfulness, sincerity and their opposite meanings, such studies have been declared as unsuitable for forensic purposes (Gagina \& Kuznetsov, 2020). In order for an expert conclusion of any kind, made individually or collectively, to be evaluated by an investigator or a court in conjunction with other evidence collected in this case and related to the subject of proof, it is necessary that it meets all the procedural requirements, including: the completeness of the study, the suitability of the materials presented, the correctness and acceptability of the use of scientifically approved methods and techniques (Rossinskaya \& Galyashina, 2017). Forensic psycholinguistic methods and comprehensive algorithms used in some forensic experts' reports to detect speech signs of lying demonstrate a great variety that contradicts with the principals of evidence admissibility. The insufficient development of the currently used expert approach and the lack of a unified methodology for solving expert tasks on a strictly scientific basis thus, demand the development of comprehensive methods for studying lies/deception on the basis of forensic speech science and cognitive theory. Expert research of witness testimony is an extremely complex area of expert practice that requires special responsibility and professionalism from experts. In accordance with Article 8 of the Federal Law on State Forensic Expert Activity in the Russian Federation, an expert must conduct research objectively, on a strictly scientific and practical basis, within the limits of the relevant specialty, comprehensively and in full. The expert's conclusion should be based on the provisions that make it possible to verify the validity and reliability of the conclusions made on the basis of generally accepted scientific and practical data. The reliability of the 
https://doi.org/10.15405/ejsbs.302

eISSN: 2301-2218 / Corresponding Author: Galyashina Elena Igorevna

Selection \& Peer-review under responsibility of the Editors

expert's conclusion should be ascertained in relation to each piece of evidence separately, and then, with all of the evidence as a whole in order to assess their sufficiency for the resolution of the case without reasonable doubt.

\section{Acknowledgements}

The reported study was funded by RFBR, project number 20-011-00190. The author(s) declare that there is no conflict of interest.

\section{References}

Adler, J. E. (1997). Lying, deceiving, or falsely implicating. Journal of Philosophy, 94(9), 435-452. https://doi.org/10.2307/2564617

Alston, W. P. (2000). Illocutionary acts and sentence meaning. Ithaca: Cornell University Press.

Amado, B. G., Arce R., \& Farina, F. (2015). Un-Deutsch hypothesis and Criteria Based Content Analysis: A meta-analytic review. The European Journal of Psychology Applied to Legal Context, 7(1), 3-12. https://doi.org/10.1016/j.ejpal.2014.11.002

Columbia University, SRI International, \& University of Colorado Boulder (2013). CSC Deceptive Speech LDC2013S09. Web Download. Philadelphia: Linguistic Data Consortium. https://doi.org/10.35111/q500-9a28

Ekici, S. (2016). Electric Load Forecasting Using Regularized Extreme Learning Machines. International Journal of Industrial Electronics and Electrical Engineering, 4(6), 119122.

Eckman, P. M. (2009). Telling Lies: Clues to Deceit in the Marketplace, Politics, and Marriage. W. W. Norton \& Company.

Engalychev, V. F., Kravtsova, G. K., \& Kholopova E. N. (2016). Forensic psychological examination to identify signs of reliability/unreliability of information reported by participants in criminal proceedings (based on video recordings of investigative actions and operational search activities): monograph. - Moscow, Yurlitinform (In Russian).

Eyben, F., Wollmer, M., \& Schuller, B. (2010). Opensmile: the mu-nich versatile and fast open-source audio feature extractor, Proceedings of the 18th ACM international $\begin{array}{llll}\text { conference on } & \text { Multimedia. }\end{array}$ https://doi.org/10.1145/1873951.1874246

Galyashina, E. I. (2020). Forensic speech science: textbook. Moscow. Norma: INFRA-M. (In Russian).

Gagina, O. V., \& Kuznetsov V. O. (2020). Methodology of psychological and linguistic research of video materials of procedural actions: influence on the content of the testimony. Moscow. RFCFS of the Ministry of Justice of the Russian Federation. (In Russian).

Gogin, A. A., \& Repeteva, O. E. (2017). Verbal offenses: concept, essence, types: electronic textbook. Togliatti: TSU Publishing House. (In Russian). 
Green, M. (2000). Illocutionary force and semantic content. Linguistics and Philosophy, 23, 435-473. https://doi.org/10.1023/A:1005642421177

Green, S. P. (2001). Lying, misleading, and falsely denying: How moral concepts inform the law of perjury, fraud, and false statements. Hastings Law Journal, 53(1), 157-212. https://repository.uchastings.edu/hastings_law_journal/vol53/iss $1 / 2$

Green, M. S. (2017). Assertion and Convention. In S. Goldberg (Ed.) The Oxford Handbook of Assertion. https://doi.org/10.1093/oxfordhb/9780190675233.013.8

Halfmann, E., \& Sporer, S. L. (2015). Belief in Context: Effects of suspect preparation time on belief about Scientific Content Analysis. EAPL + World Conference. (Abstracts, pp. 92-93). Nuremberg, Germany, 4-7 August 2015.

IAFPA Code of Practice (2020). The International Association for Forensic Phonetics and Acoustics (IAFPA) https://www.iafpa.net/

Izotova T., Kuznetsov V., \& Plotnikova, A. (2016). Methodology of Forensic Linguistic Analysis in Criminal Insult Investigations. Theory and Practice of Forensic Science, 1(41), 92-98. (In Russ.) https://doi.org/10.30764/64/1819-2785-2016-1-92-98

Kirchhübel, C. (2013). The acoustic and temporal characteristics of deceptive speech [Unpublished doctoral dissertation, The University of York]. https://core.ac.uk/download/pdf/19496297.pdf

Köhnken, G., Manzanero, A. L., \& Scott, M. T. (2015). Statement validity assessment: myths and Limitations, Anuario de Psicología Jurídica, 25, 13-19. https://doi.org/10.1016/j.apj.2015.01.004

Kirchhübel C., Stedmon A.W., \& Howard D. M. (2013) Analyzing Deceptive Speech. In Harris D. (Ed.), Engineering Psychology and Cognitive Ergonomics. Understanding Human Cognition. EPCE 2013. Lecture Notes in Computer Science, 8019. Springer, Berlin, Heidelberg. https://doi.org/10.1007/978-3-642-39360-0_15

Levitan, S. I., Levitan Y., An, G., Levine, M., Levitan, R., Rosenberg, A., \& Hirschberg, J. (2016). Identifying individual differences in gender, ethnicity, and personality from dialogue for deception detection. Proceedings of the Second Workshop on Computational Approaches to Deception Detection (pp. 40-44) https://doi.org/10.18653/v1/W16-0806

Mahon, J. E. (2008). Two definitions of lying. International Journal of Applied Philosophy, 22(2), 211-230. https://doi.org/10.5840/ijap200822216

Mahon, J. E. (2015). The definition of lying and deception. Stanford Encyclopaedia of Philosophy. https://plato.stanford.edu/entries/lying-definition/

Plotnikova, A.M., Kuznetsov, V. O., Sazhenin, I. I., Akulenko, E. V., Boitsov, A. A., Gubarenkova, E. O., Kruk, E. K., Kumkova, T. N., Portnova, V. B., \& Chumakova, E. N. (2018). Semantic research in forensic linguistic expertise: a methodological guide; S. A. Smirnova (Ed.). Moscow. RFCFS of the Ministry of Justice of the Russian Federation. (In Russian).

Rossinskaya, E. R., \& Galyashina, E. I. (Eds.) (2017). Forensic expert science: history and modernity (scientific school, expert practice, competence approach). Moscow: Prospekt. (In Russian).

Searle, J. R. (1979). A taxonomy of illocutionary acts. Expression and Meaning: Studies in the Theory of Speech Acts (pp. 1-29). Cambridge University Press. https://doi.org/10.1017/CBO9780511609213.003 
Schuller, B., Steidl, S., \& Batliner, A. (2009). The INTERSPEECH 2009 emotion challenge. Proceedings INTERSPEECH 2009, 10th Annual Conference of the International Speech Communication Association Brighton, United Kingdom, September 6-10, 2009. https://doi.org/10.21437/Interspeech.2009-103

Smirnova, S. A., Makushkin. E. V., Asnis, A. Y., Vaske, E. V., Dozortzeva, E. G., Safuanov, F. S., Shishkov, S. N., Shipshin, S. S., Oshevsky, D. S., Berdnikov, D. V., Sekerazh, T. N., \& Kalininah, A. N. (2016). Information letter "On the illegality of determining the reliability of testimony by forensic examination". Theory and practice of forensic examination, 3(43), 64-73. https://doi.org/10.30764/64/1819-2785-2016-3-64-73 (In Russian).

Supreme Court of the Russian Federation (2017). Appeal ruling of the Judicial Board for Criminal Cases, https://www.legalacts.ru/sud/apelliatsionnoe-opredelenieverkhovnogo-suda-rf-ot-07062017-n-46-apu17-6//

Twitchell, D. P., Nunamaker, Jr., J. F., \& Burgoon, J. K. (2004). Speech act profiling: A probabilistic method for analyzing persistent conversations and their participants. Thirty-Seventh Annual Hawaii International Conference on System Sciences (CD/ROM), Big Island, Hawaii, IEEE Computer Society (pp. 403-410). https://doi.org/10.1109/HICSS.2004.1265283

Vrij, A. J. (2000). Detecting Lies and Deceit: The Psychology of Lying and Implications for Professional Practice, Expert Evidence, 7(3), 227-232.

Zuckerman, M., \& Driver, R.E. (1985) Telling lies: Verbal and nonverbal correlates of deception. In A. W. Siegman, \& S. Feldstein, S. (Eds.), Multichannel Integrations of Nonverbal Behavior (pp. 129-147). Lawrence Erlbaum Associates. 